\title{
Exploring mobile learning in the Third Space
}

\author{
Sandy Schuck ${ }^{\mathrm{a}}$, Matthew Kearney ${ }^{\mathrm{a}}$, Kevin Burden ${ }^{\mathrm{b}}$ \\ ${ }^{a}$ University of Technology Sydney \\ ${ }^{\mathrm{b}}$ University of Hull
}

\begin{abstract}
Mobile learning is enabling educators and students to learn in ways not previously possible. The ways that portable, multi-functional mobile devices can untether the learner from formal institutional learning give scope for learning to be conceptualised in an expanded variety of places, times and ways. In this conceptual paper we articulate this notion by using the metaphor of the Third Space to envision what can be achieved with mobile learning. We outline our use of the metaphor, consider how it extends notions of $21^{\text {st }}$ century learning, and use a mobile pedagogical framework previously established, to provide a context for the discussion. We conclude with implications of learning in the Third Space for teachers and students. These implications suggest that roles of teachers and students and structure of the curriculum need to change to ensure we leverage the potential of mobile learning.
\end{abstract}

Keywords: mobile learning, $21^{\text {st }}$ century learning, Third Space, Mobile Pedagogical Framework, untethered learning.

\section{Introduction}

For many people, the way that they work, play and learn is changing rapidly through new opportunities provided by mobile technologies (e.g., smartphones, tablets, netbooks), opportunities to integrate the physical and virtual, to learn from experts in distant places, and to choose the time and place for such learning to occur. Commensurate with these changes is a growing interest amongst educators and researchers in the use of these increasingly multifunctional mobile devices to support student learning (Pegrum et al., 2013). Such learning is known as mobile learning or m-learning. In this paper, we adopt El-Hussein and Cronje's (2010) definition of m-learning as "any type of learning that takes place in learning environments and spaces that take account of the mobility of technology, mobility of learners and mobility of learning" (p. 20) The ubiquity of mobile devices, combined with ongoing technological developments such as geospatial and motion detection, augmented reality and context awareness (Johnson, Adams Becker, Estrada, \& Freeman, 2014), is providing an additional stimulus for educators to review their pedagogical approaches and practices (Schuck, Aubusson, Kearney \& Burden, 2013 ). Yet school learning seems anchored to past ways of conducting educational activities (Royle, Stager \& Traxler, 2014). Over fifteen years ago, a keynote speaker at a leading technology conference asked, "If we didn't have the schools we have today, would we create the schools we have today?" (Carroll, 2000, p.117). With the growing power and portability of 
mobile technologies providing more seamless access to resources and learning communities, it seems timely to revisit this question. This interesting question has provided a stimulus for this conceptual paper. The paper uses the metaphor of the Third Space to extend traditional notions of learning to include learning that is untethered from the strictures of formal classrooms and curricula.

To foreground our discussion, it is useful to consider what learning at the school level is expected to achieve to provide competent and confident citizens. Much has been written about the 21st Century learner, but this discussion appears to still be anchored in 20th Century thinking. While a range of " 21 st Century" learning skills and knowledges have been identified as necessary to effectively prepare contemporary students to be competent and effective members of society and to prepare them for future workplaces (Fullan \& Langworthy, 2014), these skills and knowledges still appear to be tethered to notions of institutional learning and fixed curricula. Employers now seek prospective employees who are competent collaborators and problemsolvers, team-players, effective communicators and creative, critical thinkers (Resnick, 2008; Mongon \& Leadbeater, 2012). They demand workers who are adaptable and able to function flexibly in less structured, shared, activity-based work environments. The place of subject matter knowledge is less emphasised; while learners who are resilient and can cope with uncertainty seem more adapted to future societal needs (Hoskins \& Crick, 2010). It is in this context of rapid and sustained change, that schools are charged with preparing students to be productive members of future societies, able to embrace the requirements of new contexts of work and personal life. Learners are no longer well served by only being exposed to traditional instructionist teaching approaches (Papert, 1994) in formal spaces designed for the needs of yesterday's society. They also need to be able to learn in new and flexible ways that prepare them to function well in tomorrow's world. Yet our ways of preparing students for this future have not changed radically and our views of effective learning are mired in past thinking.

This contradiction can be seen in the way that fixed, physical places still characterise formal learning environments, featuring relatively impermeable boundary objects such as walls, classrooms and buildings. And rigid, temporal slots such as teaching periods, timetables and semesters continue to make institutional learning relatively immutable (Traxler, 2009). However, as mobile technologies become pervasive, more flexible 'time-space' configurations (Tubin, 2006) are opening up opportunities for new ways of designing and enacting learning; ways frequently described using terms such as location-based (or place-based) learning (Jones, Scanlon \& Clough 2013), 'all the time, everywhere' learning (Norris \& Soloway, 2013), learning 'on the move' (Sharples, 2013) and in 'multiple contexts' (Mifsud 2014). These new portable devices are enabling learning in a multiplicity of formal and informal, physical and virtual contexts, ranging from structured, teacher-mediated experiences in formal spaces like school classrooms and learning management systems, to semi-formal spaces like libraries and virtual museums, to more self-regulated experiences in learner-generated, socially negotiated contexts such as coffee shops, shopping centres, public transport settings and Facebook (Ling \& Donner, 
2009; Luckin, 2010, Nortvig, 2014). In this paper, we introduce the notion of the Third Space as a metaphor for imagining learning across these diverse contexts, and as a useful way of characterising the flexible nature of 21 st Century learning for school aged students. This conceptual paper therefore poses the research questions:

1. How does the metaphor of the Third Space extend understanding of 21st Century learning?

2. How do mobile technologies facilitate learning in the Third Space?

3. How do we design learning for the Third Space mediated by mobile technologies?

Each of these research questions presents a complex problem and the purpose of the paper is not necessarily to resolve all of these conundrums, but to raise them as a stimulus for further debate across the educational community.

\section{Using the Third Space to extend notions of 21st century learning}

The term 'Third Space' has been used by some scholars in a geographical sense to refer to outof-school learning that occurs in social contexts. In this sense, the 'First space' has been interpreted as a place or institution where formal learning may occur, the 'Second space' is a site where informal learning takes place, for example, in a museum, library or home, while the 'Third space' lies somewhere 'in-between'. Oldenburg (1999) discusses the 'Third Place' as the basis of community and social life, such as a cafe or the hairdresser salon, in which more creative activity can take place.

Others have interpreted the notion of 'Third Space' in a metaphorical sense which transcends the notion of physical space. Soja (1996) was one of the first to contribute to this discussion by suggesting that the Third Space encourages the rejection of binary relationships and the consideration of new hybrid, socially produced sites for collaboration. This more abstract interpretation originated in cultural and literacy fields, where it referred to the way that different cultural texts are negotiated in different contexts. These contexts involve the re-imagining and recreation of spaces to provide an opportunity for creativity, insight and action. Zeichner (2010) introduced the concept of Third Space into teacher education to represent the hybrid space between the school and university, where theory and practice could meet. Of interest in Zeichner's discussion, and that of teacher educators who followed him, was the emphasis on boundary crossing or border spanning (Akkerman \& Bakker, 2011), including emergent, hybrid spaces for reflective practice (Flessner, 2014).

We appropriate the metaphor of the Third Space to analyse and imagine new ways of learning, with, through and around mobile technologies, to extend our notions of 21 st Century learning. We draw on the work of Soja (1996) and Zeichner (2010) to define the Third Space as an emergent shared space, providing an opportunity to develop contemporary learning skills and 
knowledges, a space that extends beyond traditional, institutional learning with rigid, temporal schedules to also include the spaces of more spontaneous, often incidental learning, unconstrained by classroom walls and set schedules, and sometimes free from teachers and prescribed curricula. The characteristics of transformation, hybridity, fluidity, and boundarycrossing make the Third Space a useful metaphor to use in exploring contemporary learning in and beyond school, learning that is enacted in both formal, structured learning environments and unpredictable, emergent, learner-generated spaces. While learning across the latter spaces has existed for many years (for example, language learning in situ in early childhood, learning to drive a car, participation in citizen science projects), it has been divorced from formal learning. It is the ubiquity and portability of mobile technologies that now assist contemporary learning to be seamless, connected and accessible, thus demanding a re-examination of the possibilities afforded through m-learning.

The language of binaries is increasingly unhelpful in assisting our understanding of the emerging complex landscape of 21 st Century learning. Previous distinctions between binaries such as formal and informal learning, physical and virtual locations, between learning at school and home or campus and workplace, even notions of public and private or leisure and work or local and global, do not necessarily hold meaning in this new contemporary learning landscape (see Figure 1). The metaphor of the Third Space, with its emphasis on boundary-crossing and hybridity helps to conceptualise the possibilities afforded by m-learning.

\section{$<$ Insert Figure 1 here $>$}

The Third Space conceptualisation of contemporary learning requires a new language to expand our understanding of 21 st Century learning. A revision of the language of binaries, which includes transitions from one space to another, and multiple boundary crossings, is needed. For example, notions of synchronous and asynchronous communications have been blurred, for instance, in the instantaneous access to emails provided by mobile data connectivity, (Dalgarno, 2014) and the term 'polychronous' learning has been promoted as an alternative to this binary position (Oztok et al., 2014). Similarly, Roth and Erstad (2013) emphasise that mobile practices, especially networking between learners, are 'polycontextual' in the sense that they are not bounded by one context and "have the potential to be realised in a range of strata and situations based on participation in multiple settings" (p.125). Nortvig (2014) introduces the similar concept of 'multi-locality' to help describe the range of ways that teachers and students can be present (synchronously and asynchronously) in physical and virtual spaces. For example, 'multilocal asynchronous' settings are often seen in learner generated contexts, typically involving self-directed studies, where students work "in several physical and virtual spaces across time" (p. $615)$. 
The metaphor of the Third Space helps us move away from current notions of 21 st Century learning that are still bounded by 20th Century concepts of school learning. It allows us to consider learning that includes but is not restricted to classrooms, set curricula, and authoritative teachers. We argue that to develop the flexibility, autonomy, collaboration and resilience required in 21st Century learning, we need to extend current views of learning, views that anchor learning to classrooms, rooted in traditional concepts of time and place. We need to acknowledge the choices that learners have today for the nature, time and place of their learning, choices that far exceed what is offered in contemporary schooling.

\section{Mobile technologies as facilitators of learning in the Third Space}

The affordances of mobile technologies and their ubiquity encourage the construction of new understandings of learning in the Third Space. Mobile technologies allow learning to occur across boundaries and contexts. We call the learning that occurs using these technologies, mobile learning (or m-learning). In this section, we examine how m-learning facilitates activities in the Third Space, activities that are characterised by seamless learning and go beyond the binaries noted above. The characteristics of m-learning, that is, its untethered nature, and its blurring of binaries, fit well with the Third Space metaphor and provide an opportunity to understand $21 \mathrm{st}$ century learning in new ways.

We use the Third Space to indicate how m-learning may articulate a new space for contemporary learning, one that has been described in other domains (e.g., Jónsdóttir, Gísladóttir \& Guðjónsdóttir, 2015; Taylor, Klein \& Abrams, 2014) as reflective, productive, with potential for providing new opportunities, and for reconsidering roles. Bower, Cram and Groom (2010, p.129) describe the opportunities provided by emerging technologies as "creating a new kind of reality, one in which physical and digital environments, media and interactions are woven together throughout our daily lives". It is this reality to which we refer with our metaphor of Third Space.

Recent studies have focused on the notion of using handheld devices to explore 'seamless learning' tasks (Hedberg \& Stevenson, 2014; Rushby, 2012; Toh, So, Seow, Chen \& Looi, 2013), supporting a transition of learning across contexts, often between formal and informal learning spaces. For example, some of these authors discuss the 'breaking away from text, time and place" (Hedberg \& Stevenson, 2014, p.17) and others discuss connecting learning in and out of class, in and out of school, connecting learning across curricular and extra-curricular activities, learning that is social or personal, academic or recreational, that exists in physical or virtual contexts and across times and locations (Wong \& Looi, 2011). 'Seamless learning' might connect learning between school and excursion sites, providing a bridge between classroombased tasks and more realistic fieldwork settings; or providing a transition from a personal, informal learning episode at home to learning at a later time at school. We build on and expand 
on this notion of using mobile technologies to support 'seamless learning' with the construct of m-learning in the Third Space.

To illustrate m-learning in the Third Space, we provide three examples. The first is a teacher mediated example, while the second example is student initiated. The third example is a hybrid, initially stimulated by the teacher but then driven entirely by the students. The first example is a secondary school Visual Arts learning task designed by a teacher participating in our 2015 study (Kearney, Burden \& Rai, 2015). The students in this task used their mobile devices to enhance interactions during an excursion to a seaside sculpture exhibition. Students created their own photographs and video recordings at the 'Sculpture by the Sea' site, critiquing the artefacts by sharing their thoughts through Twitter and other social media. They also used a QR reader application (app) to interact with the artworks and obtain further information. These activities facilitated face-to-face discussion at the site and back in the classroom after the excursion, and promoted online conversations on social media (through a class hashtag) between students in unknown physical locations.

The second example illustrates how learners are capable of initiating their own learning activity through the playing of the popular multiplayer game, Minecraft, on their personal mobile devices. In this example, which is part of a larger study (Niemeyer \& Gerber, 2015) into the use of Minecraft as part of the digital 'maker culture', one of the participants in the study used his cell phone to play the pocket edition of the game with other users around the world. He created over 280 video tutorials on YouTube, which were viewed 1.8 million times, to explain to others how to play the game and this attracted over 7000 subscribers. In these instructional videos viewers posed questions and raised issues which were answered by the creator of the video and the community of subscribers in a highly constructionist and collaborative manner. The playing and interactions take place in multimedia rich virtual spaces, are learner-initiated and learnerdesigned and are what Henry Jenkins refers to as 'transmedia learning' (Jenkins, 2015). The learning of strategies, problem solving and collaboration occurring in this example would then serve the learners well in the classroom.

The third example illustrates how learners initiated their own collaborative activity based on a stimulus question posed by their teacher, in a study conducted in 2015 (Schuck, Maher \& Perry, 2015). Students were challenged to develop their own set of mathematical laws/axioms by their mathematics teacher. They independently set up a cloud-based collaborative site and shared their ideas there through their mobile devices, without the teacher being aware of this activity. Their activity in this virtual space took place out of school over a period of a few days and the results were brought to the teacher's attention after the students had concluded the activity. These results then formed the basis of a lesson.

Mobile learning in the Third Space raises some confronting questions about what is important (and what is no longer important) in 21 st Century teaching and learning. For example, is it still 
critically important that learning predominantly takes place in a classroom? What can be learned at home or in a cafe, or outdoors in a school playground? How important is the rigid scheduling of school-based learning? Does it matter if students learn Mathematics at a scheduled time in the school timetable or at an 'after-hours' time at the learner's discretion? We propose that traditional time and space configurations of formal education are no longer critically important and indeed are seen by some young people as irrelevant (Hedberg \& Stevenson, 2014). It is evident that learners and teachers already negotiate times and use mobile technologies to generate their own spaces to enact a more flexible style of learning (Hedberg, 2011, Traxler, 2009). To leverage the benefits of these new contexts for learning, we argue that task designs are still vitally important and need to take account of distinctive pedagogical affordances of $\mathrm{m}$ learning (Kearney et al., 2012; Kearney, et al., 2015; Royle, Stager \& Traxler, 2014). Educators need a more nuanced appreciation of a range of new contexts for learning and a broader understanding of designing learning across these contexts.

\section{Designing for learning in the Third Space}

\section{Re-thinking contexts for learning}

From a socio-cultural perspective (Wertsch, 1991), any discussion of learning design starts with the learner's context (see the core of our model in Figure 2). Given these contexts are increasingly unpredictable, flexible and often specific to learners (Kukulska-Hulme, 2010a), educators need to recognise more emancipatory possibilities and revise, and where necessary challenge, assumptions underpinning traditional notions of learning environments. There is a need to acknowledge that mobile learning can occur beyond the familiar physical and virtual spaces such as classrooms, homes and online Learning Management Systems (LMS), and may occur without a teacher, initiated by learners and in the presence of peers and experts from around the globe.

Designing for learning in the Third Space demands a review of assumptions underpinning traditional learning contexts. Formal learning environments that are prevalent in institutions have a set of underpinning assumptions about teaching and learning. From a temporal perspective, learners in schools are expected to learn in 'chunks' of allocated times in the year, at scheduled times of the day and week. This arrangement tends not to recognise or value learning outside these set times, and is somewhat contradictory to the often spontaneous, incidental nature of mobile learning. From a spatial perspective, the environments where this learning takes place often indicate assumptions about whether the learning should be collaborative. Traditional physical learning spaces such as lecture theatres, or formal virtual spaces such as learning management systems, usually assume a delivery model of learning (Tanner, 2000) in which the teacher is charged with expertise and authority to disseminate knowledge to passive learner recipients. In contrast, other spaces will suggest a more participative, collaborative mode by being set up with tables and other furniture around which learners sit, or by making use of online 
networks and learner-generated content in social, virtual communities. For example, informal learning in digital spaces assumes that learners are self-directed and autonomous. Young people using these spaces choose what they learn and operate at their own pace and in their chosen way. These informal, often recreational spaces (such as multiplayer games) are typically situated in learning networks and communities, and require collaboration, problem-solving and other inquiry-based processes. The emphasis is on interaction with peers and creation with new media (Aubusson, Griffin \& Kearney, 2012). The experience of mobile learners in these types of digital habitats (Wenger, White \& Smith, 2009) can clash with the dominant modes of traditional formal learning.

To design in the Third Space, educators need to anticipate and facilitate seamless 'boundary crossing' across learning spaces. Portable devices are a conduit to 'learning on the move' (Sharples, 2013) and can mediate this 'flow of learning' between contexts, for example, through the use of microblogging, social networking platforms, simulations or games (Lai, Khaddage \& Knezek, 2013). Educators need to incorporate ways of leveraging the flexibility of boundary crossing to enhance learning across a multitude of contexts. For example, a student may start the day by travelling to school, spontaneously interacting with friends in a less formal virtual space on Facebook (e.g., to discuss a homework problem), arrive at school and work with others or alone on the task and then continue with this work at home. Educators need to cater for this type of movement between known and unpredictable, learner-generated (physical and virtual) spaces and all of these spaces need to be recognised and valued as legitimate places for learning.

Learning takes place in a range of contexts with a multitude of time and place configurations (Nortvig, 2014; Roth \& Erstad, 2013). Learning may take place 'polysynchronously' (Oztok et al., 2014), across these spaces, possibly causing challenges for educators who are not used to thinking about this flexible use of time. Designing for learning in the Third Space aims to recognise opportunities for and even anticipate contexts that may elicit incidental, spontaneous learning interactions; and also plan for pre or post-episodic asynchronous learning conversations. After acknowledging and indeed anticipating this highly malleable nature of place and time, signature mobile pedagogies (Kearney et al., 2015) can be considered for designing learning in the Third Space.

\section{Supporting collaborative, personalised and authentic learning}

To aid in thinking about designing for mobile learning in the Third Space, we base the following discussion on the Mobile Pedagogical Framework, developed by the authors (Kearney et al., 2012). This framework is helpful for educators to think about designing learning in the Third Space. It is informed by a socio-cultural perspective (Wertsch, 1991), highlighting three central and distinctive pedagogical features of mobile learning: collaboration, personalisation, and authenticity. Consistent with this perspective, how learners experience these signature mobile 
pedagogical features is influenced by the 'time-space' organisation of the learning contexts (Ling \& Donner, 2009): "the organisation of the temporal (scheduled/flexible; synchronous/asynchronous /polysynchronous) and spatial ( , formal/informal, physical/virtual) aspects of the m-learning environment" (Kearney et al., 2015, p.49), as depicted in Figure 2.

$<$ Insert figure 2 here $>$

Two sub-themes for each of the three features are included in the diagram, pinpointing the critical features of m-learning from a pedagogical perspective.

Collaboration. Collaboration consists of conversation and data sharing sub-themes, highlighting learners' use of networked connections and interactions with peers, teachers and other people, exchanging ideas and sharing resources through rich collaborative tasks (Wang \& Shen, 2012). This construct encompasses the multimodal, communicative aspects of m-learning (Sharples, Taylor \& Vavoula, 2007) and the information seeking, media production and sharing characterized by mobile learning behaviour (Mills, Knezek \& Khaddage, 2014). The type of collaboration afforded by the Third Space would typically occur across a range of networks. Participative learning in local and global communities provides an effective bridge for seamless transitions between Third Space environments, including private, semi-private and public networks. These networks allow learners to collaborate with peers and teachers in their local community (e.g., school-based classes) as well as unknown peers and experts in larger communities. Our thinking about this environment is supported by Royle, Stager and Traxler (2014, p.34) who note that: "Though learning was once bounded by time and place, now, with mobile devices, it can seamlessly retrofit any human interaction to, as Dewey put it, emancipate the mind"

Membership of these communities, can be initiated and controlled by learners to give them agency over what networks they participate in. They can interact with peers and other experts in private spaces or 'walled gardens' (Sharples, Graber, Harrison \& Logan, 2009) such as password-protected Facebook groups or more public communities such as multiplayer games, Instagram, Twitter or other social media spaces.

Students' network literacy skills (Pegrum, 2010; Rheingold \& Weeks, 2012) become paramount for learners to effectively find, manage, navigate and participate in these spaces. These skills include students' ability to evaluate and select suitable groups in their immediate context, to effectively use the group's nuanced social rules for interactions, and to become visible and build their own identity within the group through production and sharing of knowledge artefacts (Kukulska-Hulme, 2010a). Development of learners' cultural competencies (Kukulska-Hulme, 2010b) and multimodal literacy skills also become crucial to operate across these spaces as 
learners participate in increasingly global communities and communicate across language and cultural barriers.

Personalisation. Personalisation consists of the sub-themes of agency and customisation. "High levels of personalisation would mean the learner enjoys a high degree of agency in appropriately designed m-learning experiences, with the ability to customise and tailor both tools and activities, driven by a strong sense of ownership" (Kearney et al., 2015, p.49). This construct includes the opportunity for learners to gather immediate, customised feedback tailored to their own context (Zhang et al., 2010), for example in multi-user mobile gaming environments. Third Space task designs need to both recognise and to privilege increased levels of autonomy and ownership of the learning process (when, where and how learning occurs). For example, tasks for the Third Space inherently involve students choosing their own resources and local information for learning. The increasing levels of student ownership of devices means that learners now take control of their own learning technologies. This is a significant shift from the decades of teacher and institutional 'micro-management' of educational technologies and the 'forced adoption' and appropriation of software 'handed down' from the corporate world (Royle et al., 2014). Hence, tasks need in-built flexibility to allow students to use their own personally selected resources for learning across a variety of spaces, for example, the freedom to choose relevant content and 'apps' that are tailored to their own unique learning needs in their immediate context. This includes choosing tools such as Storify or new media authoring tools to develop multi-modal representations of their 'learning stories' and knowledge development. To optimise these more autonomous processes, students need to develop navigation and evaluation skills to build up their competence to move between spaces using appropriate tools (Rantala, 2009).

Tasks for the Third Space also need to be designed to take advantage of a multitude of opportunities for personally tailored feedback. Learners in the Third Space can utilize numerous sources of spontaneous and planned feedback across a variety of spaces including teachers and outside experts, peers and their own natural and virtual environments. Emerging "context-aware capabilities" allow devices to acquire information about the user and their immediate environment (e.g., time, location, nearby people and objects), presenting unique opportunities for automatic feedback during learning experiences. For example, emerging augmented reality applications and wearable activity-tracking devices with geolocation capabilities, offer customised interactions with 'The Internet of Things' (Johnson, Adams Becker, Estrada, \& Freeman, 2014) and promise ways for learners to select and apply information to self-assess their own progress (Kranz et al., 2013). The increased access to data analytics demands new literacies from students, including the ability to read, analyse and interpret evidence to assess and respond to current levels of 'in-situ' performance. Teachers need to legitimise this wider range of feedback sources for their students, and prepare them to become more astute in recognising and utilising spontaneous, serendipitous opportunities for formative feedback. 
Authenticity. This construct highlights contextualised, participatory, situated learning across the Third Space, providing real world relevance and personal meaning to the learner. The subthemes of contextualisation and situatedness "bring to bear the significance of learners' involvement in rich, contextualised tasks (e.g., realistic setting and use of tools), involving participation in real-life, in-situ practices" (Kearney et al., 2015, p.49). The Third Space metaphor anticipates and facilitates boundary crossing across spaces that will ultimately carry varied perceptions of personal relevance for learners (Burden \& Kearney, 2016). However, given these physical and virtual contexts (and the resources used in them) are invariably chosen by learners (Cochrane \& Antonczak, 2014; Pachler et al., 2009), they are likely to carry high levels of personal meaning, particularly those emergent tasks that are less prescribed and are learner-negotiated (Burden \& Kearney, 2016; Kearney et al., 2015).

It is likely that the development of activities in the Third Space will lead to a change of student perceptions about what is authentic. There is a need to acknowledge that the flexible, boundary crossing experience of Third Space learning is becoming more common and accessible, given the mounting evidence of young people's digital activities and experiences in recreational spaces (Erstad \& Sefton-Green, 2012; Royle et al., 2014).

\section{Implications of learning in the Third Space}

There are many implications for teachers and students that arise from recognition of new ways of learning facilitated by mobile technologies, and using the metaphor of the Third Space. These implications include the negotiation of new roles for teachers and students, teacher dispositions, a possible broadening of curriculum, accountability for schools, and ethical principles. We suggest that we also need to think differently about learning and ask questions concerning the ownership and direction of learning, the curriculum, and valued knowledge.

We argue that learning in the Third Space should not be restricted by 20th century notions of time, place and curriculum for learning. Teachers need to prepare to support critical and creative thinkers for the creative society (Resnick, 2008), and encourage the take-up of pedagogical opportunities afforded by use of mobile learning.

\section{Changing teacher and student roles}

It is challenging for teachers to conceptualise new roles for themselves. Contemporary teacher education programs should assist in preparing teachers for different roles: roles as co-learners, as part of networked communities, assisting other learners who may be in distant contexts or in local ones. Teacher identity shift is likely to occur as for many, the fundamental notion of being a teacher is challenged by ideas of teaching in the Third Space. This shift holds some risk as the new ways of learning might undermine teacher controlled teaching approaches and teacher position in a results-oriented culture (Royle, Stager, \& Traxler, 2014, p.39). Teachers in the 
Third Space do not need to be the sole authorities for summative and especially formative assessment of learners. As discussed previously (see earlier section), learners can evaluate evidence and self-assess their learning, while applications and global experts can provide instant formative feedback to students. Further, teachers need to be on the lookout for spontaneous and authentic teaching moments, which could occur in a range of times and places.

Students too need to be able to negotiate new roles for themselves, as self-directed learners, as members of global communities, and as initiators and assessors of their own learning. They need to know who to approach for assistance and guidance in their learning, as this may not necessarily be their local teachers. Learning should be about developing initiative, skills in knowledge production and communication (as per Kukulska-Hulme, 2010a).

\section{Teacher dispositions}

It is clear from the examples above that a range of teacher dispositions are needed to manage learning in the Third Space. Most importantly teachers need to be open to change. They need to recognise and accept that the learners in their charge are entering an ever-changing world. Their role is to travel into that changing world both with their students, and as learners themselves.

As mobile technologies continue to proliferate and diversify in their potential pedagogical affordances, there has been a tendency for teachers to default to traditional teaching approaches in formal classroom or formal virtual settings (Norris \& Soloway, 2013), focusing on teacherdirected approaches and content delivery, retrofitting "traditional pedagogical strategies and pre-existing course materials onto mobile devices and social media" (Cochrane \& Antonczak, 2014, p.359). Mobile technologies are too often seen by teachers as "delivery systems for teaching or training content as much as they are seen as digital tools for learning embedded into the fabric of people's lives" (Royle, Stager, \& Traxler, 2014, p.34). Such perceptions need to change if formal education is to be seen as relevant to future generations. Teachers need to skill themselves in the digital literacies of the Third Space so that they can recognise the opportunities for personalised, authentic, collaborative learning in this space and are able to support such learning.

\section{Curriculum change}

To optimise learning in the Third Space, and support new pedagogical opportunities in these spaces, education needs to become less constrained by formal curriculum designs. In Third Space environments where learning takes place autonomously in unpredictable contexts following unplanned, unscheduled pathways, more flexible notions of curricula are needed. Educators need to revisit calls for re-conceptualising education, to allow students' imagination and play to drive student learning, and promote a creative society (Resnick, 2002) whereby 
"success is based not on what you know, but on your ability to think and act creatively" (p.18). This involves recognition of self-initiated learning across the Third Space, driven by learners' personal interests (e.g., photography or robotics).

There is a need to frequently review the knowledge, skills and understandings needed to become an effective and functional citizen in this fast-changing, contemporary creative society. Educators need to question prescribed discipline 'content' imposed and legitimised by policy makers and curriculum designers and to re-imagine more flexible curricula, inclusive of "informal funds of knowledge" (Roth \& Erstad, 2013) and supportive of new roles of mobile technologies in supporting knowledge creation across broader, contextualised learning frontiers.

\section{Accountability}

While there is great potential in m-learning for self-assessment and instantaneous feedback to the learner, it is also the case that schools need to be able to provide information on their students' learning to external stakeholders. A challenge for schools is to provide formal assessments that are facilitated by the new tools. It would be useful to reconceptualise standardised high stakes external examinations to ensure they are measuring appropriate skills and knowledge required in contemporary society. Such assessment tasks could use mobile technologies and utilise the thinking behind the Third Space to ensure authenticity and relevance. The not.school project (Heppell, 2004) was an early example of how mobile technologies were used for high stakes testing for marginalised students who were learning in informal spaces. The other areas that would need consideration in the Third Space include the duty of care responsibilities of the school, which include care for students in their charge.

\section{Ethical principles}

One of the dangers of the new freedoms afforded by learning in the Third Space is that values and ethical principles formed in this marketplace of ideas might not be ones that support a tolerant and just society. One of the principal design features of learning in the Third Space, therefore needs to be concerned with the development of high ethical principles. Discussion about the notions of public and private is relevant. While connectivity and use of mobile devices may elicit episodes of bullying, racism and stalking amongst youth, it becomes essential to design m-learning tasks to highlight the unacceptability of these practices. An example of such in situ learning is a discussion recently that took place on Twitter regarding a campaign where citizens offered to travel on public transport with any passengers who were feeling uncomfortable and anxious about racist attacks (\#Illridewithyou). The values and ethical principles arising in this example are valuable material for learning about racism and how to prevent it.

\section{Conclusion}


In this paper, we have argued that the Third Space provides a way to extend and increase the power of 21 st Century learning. The potential of m-learning to provide new and different ways of learning has been highlighted. The key characteristics of m-learning environments appear to be the malleable nature of spaces and time. We contend that our Mobile Pedagogy Framework (Kearney et al., 2012) can help educators to think about how to design learning across increasingly blurred, shifting temporal and spatial boundaries.

Designing for learning in Third Space demands the facilitation of learning in a digitally connected world. New spaces can be both productive and constraining. Mifsud (2014) and Traxler (2009) argue that many of the features of m-learning are in conflict with traditional classroom-based learning, making the effective use of m-learning a challenge for educators. The characteristic of the Third Space as a "contested space" (Bhabha, 1994) can lead to resistance and there is a need for leadership in recognising and managing these tensions.

Education is at risk of becoming irrelevant if we stay with a traditional, standardized model (Royle et al., 2014). A new paradigm for learning and an effective language to describe new ways of learning are needed. In some ways these calls are not new, as Papert (1996) reminds us:

"It is 100 years since John Dewey began arguing for the kind of change that would move schools away from authoritarian classrooms with abstract notions to environments in which learning is achieved through experimentation, practice and exposure to the real world." (p.1)

The Third Space metaphor provides a new language that helps us imagine more authentic, participative ways of learning in the 21 st Century. We urge educators to consider how Dewey's long-awaited aspirations might be fulfilled by embracing opportunities for mobile learning in the Third Space.

\section{REFERENCES}

Akkerman, S. F., \& Bakker, A. (2011). Boundary crossing and boundary objects. Review of Educational Research, 81(2), 132-169.

Aubusson, P., Griffin, J., \& Kearney, M. (2012). Learning beyond the classroom: Implications for school science . In B. Fraser, K. Tobin \& C. McRobbie (Eds.), The Second International Handbook of Science Education (pp.1123-1134). Dordrecht, The Netherlands: Springer.

Bhabha, H.K. (1994). The location of culture. London, Routledge

Bower, M., Cram, A., \& Groom, D. (2010). Blended reality: Issues and potentials in combining virtual worlds and face-to-face classes. In C. H. Steel, M. J. Keppell, P. Gerbic \& S. Housego (Eds.), Curriculum, technology \& transformation for an unknown future. Proceedings ASCILITE, Sydney (129-140). 
Boyd, D. (2014). It's Complicated: the social lives of networked teens. Yale University Press. Burden, K., \& Kearney, M. (2016). Conceptualising authentic mobile learning. In D. Churchill, J. Lu, T. Chiu \& B. Fox (Eds), Mobile Learning Design: Theories and Application (pp.2742). Singapore: Springer.

Carroll, T. (2000). If we didn't have the schools we have today, would we create the schools we have today? Contemporary Issues in Technology and Teacher Education, 1(1), 117-140.

Cochrane, T., \& Antonczak, L. (2014). Implementing a mobile media framework for designing creative pedagogies. Social Sciences, 3(3), 359-377.

Dalgarno, B. (2014). Polysynchronous learning: A model for student interaction and engagement. In B. Hegarty, J. McDonald, \& S.-K. Loke (Eds.), Rhetoric and reality: Critical perspectives on educational technology. Proceedings ASCILITE Dunedin 2014 (pp. 673-677).

El-Hussein, M. O. M., \& Cronje, J. C. (2010). Defining mobile learning in the higher education landscape. Educational Technology \& Society, 13 (3), 12-21.

Erstad, O., \& Sefton-Green, J. (2012). Identity, community, and learning lives in the digital age. Cambridge: Cambridge University Press.

Flessner, R. (2014). Revisiting reflection: Utilizing Third Spaces in teacher education. The Educational Forum, 78(3), 231-247.

Fullan, M. \& Langworthy, M. (2014). A rich seam: How new pedagogies find deep learning, London: Pearson.

Gutiérrez, K. D. (2008). Developing a sociocritical literacy in the third space. Reading Research Quarterly, 43(2), 148-164.

Hedberg, J. G. (2011). Towards a disruptive pedagogy: Changing classroom practice with technologies and digital content. Educational Media International, 48(1), 1-16.

Hedberg, J. G., \& Stevenson, M. (2014). Breaking away from text, time and place. In M. G. D. Ifenthaler (Ed.) Curriculum Models for the 21st Century (pp. 17-33). New York: Springer.

Heppell, S. (2004). The not.school project. Retrieved from ttp://history.notschool.net/future.html Hoskins, B., \& Crick, R. D. (2010). Competencies for learning to learn and active citizenship: Different currencies or two sides of the same coin? European Journal of Education, 45(1), 121-137.

Jenkins, H. (2015, April 23). Minecraft and the future of transmedia learning [Web log post]. Retrieved from http://henryjenkins.org/2015/04/minecraft-and-the-future-of-transmedialearning.html

Johnson, L., Adams Becker, S., Estrada, V., \& Freeman, A. (2014). NMC Horizon Report: 2014 K-12 Edition. Austin, Texas: The New Media Consortium

Jones, A., Scanlon, E., \& Clough, G. (2013). Mobile learning: Two case studies of supporting inquiry learning in informal and semiformal settings. Computers \& Education, 61, 21-32.

Jónsdóttir, S. R., Gísladóttir, K. R., \& Guðjónsdóttir, H. (2015). Using self-study to develop a Third Space for collaborative supervision of Master's projects in teacher education. Studying Teacher Education, 11(1), 32-48.

Kearney, M., Burden, K., \& Rai, T. (2015). Investigating teachers' adoption of signature mobile pedagogies. Computers \& Education, 80, 48-57 
Kearney, M., Schuck, S., Burden, P., \& Aubusson, P. (2012). Viewing mobile learning from a pedagogical perspective. Journal for Research in Learning Technology, 20(3), 1-17.

Kranz, M., Möller, A., Hammerla, N., Diewald, S., Plötz, T., Olivier, P., \& Roalter, L. (2013). The mobile fitness coach: Towards individualized skill assessment using personalized mobile devices. Pervasive and Mobile Computing, 9(2), 203-215.

Kukulska-Hulme, A. (2010a). Mobile learning as a catalyst for change. Open Learning, 25(3), 181-185.

Kukulska-Hulme, A. (2010b). Learning cultures on the move: Where are we heading? Journal of Educational Technology \& Society, 13(4), 4-14.

Lai, K. W., Khaddage, F., \& Knezek, G. (2013). Blending student technology experiences in formal and informal learning. Journal of Computer Assisted Learning, 29(5), 414-425.

Ling, R., \& Donner, J. (2009). Mobile communication: Digital media and society series. Maiden, MA: Polity Books.

Luckin, R. (2010). Re-designing learning context: Technology-rich, learner-centred ecologies. London: Routledge.

Mifsud, L. (2014). Mobile learning and the socio-materiality of classroom practices. Learning, Media and Technology, 39(1), 142-149.

Mills, L. A., Knezek, G., \& Khaddage, F. (2014). Information seeking, information sharing, and going mobile: Three bridges to informal learning. Computers in Human Behavior, 32, 324334.

Mongon, D., \& Leadbeater, C. (2012). School leadership for public value: Understanding valuable outcomes for children, families and communities. London: Institute of Education.

Niemeyer, D., \& Gerber, H. (2015). Maker culture and Minecraft: implications for the future of learning, Educational Media International, 52 (3), 216-226,

DOI: $10.1080 / 09523987.2015 .1075103$

Nortvig, A. (2014). The change of time and space in e-learning. American Journal of Educational Research, 2(8), 612-616.

Norris, C., \& Soloway,E. (2013). A conclusive thought: The opportunity to change education is, literally, at hand. In G. Trentin \& M. Repetto, (Eds.), Using network and mobile technology to bridge formal and informal learning (pp. 209-220). Chandos Publishing: Oxford.

Oldenburg, R. (1999). The great good place: Cafes, coffee shops, bookstores, bars, hair salons and other hangouts at the heart of a community (2nd edn). New York: Marlowe \& Company.

Oztok, M., Wilton, L., Lee, K., Zingaro, D., Mackinnon, K., Makos, A., Phirangee, K., Brett, C., \& Hewitt, J. (2014). Polysynchronous: Dialogic construction of time in online learning. ELearning and Digital Media, 11(2), 154-161.

Papert, S. (1994). Children's machine: Rethinking school in the age of the computer. NY: Basic Books.

Papert, S. (1996). Computers in the classroom: Agents of change. The Washington Post Education Review, 27. Retrieved 7 August 2015 from http://www.papert.org/articles/ComputersInClassroom.html 
Pegrum, M. (2010). 'I link, therefore I am': Network literacy as a core digital literacy. E-learning and Digital Media, 7(4), 346-354.

Rantala, L. (2009). In search of third spaces in media education: An ethnographic study from fifth graders' media workshop. Pedagogy, Culture \& Society, 17(3), 385-399.

Resnick, M. (2002). Rethinking learning in the digital age, In G. Kirkman (Ed). The global information technology report: Readiness for the networked world. Oxford: Oxford University Press.

Resnick, M. (2008). Sowing the seeds for a more creative society. Learning and Leading with Technology, 35(4), 18-22.

Rheingold, H., \& Weeks, A. (2012). Net smart: How to thrive online. MIT Press.

Roth, S., \& Erstad, O. (2013). Networked lives for learning: Digital media and young people across formal and informal contexts. In G. Trentin \& M. Repetto (Eds.), Using network and mobile technology to bridge formal and informal learning (pp. 119-152). Chandos Publishing: Oxford.

Royle, K., Stager, S., \& Traxler, T. (2014) Teacher development with mobiles: Comparative critical factors. Prospect, 44, 29-42.

Rushby, N. (2012). Editorial: An agenda for mobile learning. British Journal of Educational Technology, 43(3), 355-356.

Schuck, S., Maher, D., \& Perry, R. (2015). Moving classrooms to Third Space learning: Investigating mobile-intensive pedagogies in schools. Report for Microsoft.

Schuck, S., Aubusson, P., Kearney, M., \& Burden, K. (2013). Mobilising teacher education: A study of a professional learning community. Teacher Development, 17(1), 1-18

Sharples, M. (2013). Mobile learning: research, practice and challenges. Distance Education in China, 3(5), 5-11.

Sharples, M., Graber, R., Harrison, C., \& Logan, K. (2009). E-safety and Web 2.0 for children aged 11-16. Journal of Computer Assisted Learning, 25(1), 70-84.

Sharples, M., Taylor, J., \& Vavoula, G. (2007). A theory of learning for the mobile age. In R. Andrews \& C. Haythornthwaite (Eds.), The SAGE handbook of e-learning research (pp. 221224). Sage: London.

Soja, E. W. (1996). Thirdspace: Journeys to Los Angeles and other real-and-imagined places. Oxford: Blackwell.

Tanner, C. K. (2000). The influence of school architecture on academic achievement. Journal of Educational Administration, 38(4), 309-330.

Taylor, M., Klein, E. J., \& Abrams, L. (2014). Tensions of reimagining our roles as teacher educators in a third space: Revisiting a co/autoethnography through a faculty lens. Studying Teacher Education, 10(1), 3-19.

Toh, Y., So, H. J., Seow, P., Chen, W., \& Looi, C. K. (2013). Seamless learning in the mobile age: A theoretical and methodological discussion on using cooperative inquiry to study digital kids on-the-move. Learning, Media and Technology, 38(3), 301-318. 
Traxler, J. (2009). Learning in a mobile age. International Journal of Mobile and Blended Learning, 1(1), 1-12.

Tubin, D. (2006). Typology of ICT implementation and technology applications. Computers in the Schools, 23(1-2), 85-98.

Wang, M., \& Shen, R. (2012). Message design for mobile learning: Learning theories, human cognition and design principles. British Journal of Educational Technology, 43(4), 561-575.

Wenger, E., White, N., \& Smith, J. D. (2009). Digital habitats. Stewarding technology for communities. Portland, OR: CPsquare.

Wertsch, J. V. (1991). A sociocultural approach to socially shared cognition. In L. B. Resnick, J. M. Levine, S. D. Teasley (Eds.), Perspectives on socially shared cognition. USA: APA

Wong, L. H., \& Looi, C. K. (2011). What seams do we remove in mobile-assisted seamless learning? A critical review of the literature. Computers \& Education, 57(4), 2364-2381.

Zeichner, K. (2010). Rethinking the connections between campus courses and field experiences in college-and university-based teacher education. Journal of Teacher Education, 61(1-2), 8999.

Zhang, B. H., Looi, C. K., Seow, P., Chia, G., Wong, L. H., Chen, W., So, H. J., Soloway, E., \& Norris, C. (2010). Deconstructing and reconstructing: Transforming primary science learning via a mobilized curriculum. Computers \& Education, 55(4), 1504-1523. 